\title{
To See Without Being Seen: Landscape perception and human behaviour in urban parks
}

\author{
LWG Kawshalya*1, Janaka Dharmasena² \\ $1 \& 2$ University of Moratuwa, Moratuwa \\ *Correspondence E-mail: gaya3kawshalya93@gmail.com
}

\begin{abstract}
The ambiguous relationship between people and the environment runs back to millions of years and the concept of 'to see without being seen' has evolved from the past. As Appleton claims, the genes of our ancestors who preferred such environments are still with us and we prefer environments with our biological instincts. In this paper, four different urban restorative environments have been examined to test the 'prospects' and 'refuges' preference of the users of those places. This is tested under four aspects of the 'prospects-refuges' relationship such as; Strong prospect (open view, open observing point), Inversely balanced (close view, open observing point), Perfectly balanced (open view and closed observing point) and Strong refuge (close view and close observing point) in order to inquire about the subjective perspective of preference which claims that preferences are based on individuals. The paper explores the perception of Beddagana wetland park, Sri Jayawardenepura Kotte and Diyasarupark, Thalawathugoda prevalent among the every-day users as well as the experts in the landscape design field. The paper demonstrates that the highest preferences of both the user groups have been towards the 'Perfectly balanced' prospect refuge scenario which supports the ability to see without being seen. The paper argues that this result may be useful in designing specific spaces of urban landscapes.
\end{abstract}

Keywords:Landscape perception, subjective, prospect, refuge, urban restorative environment

\section{Introduction}

Many Urban parks have been built and developed in the recent past in and around urbanized cities. Although many of them seem successful, there are some designed open public spaces which are underused or are being ignored by the people. The main reason behind this has been the improper designing practices which have left behind the user preferences and perceptions in the process of design. (Han, 2003)

Rapid urbanization has led to many adverse environmental conditions all around the world, such as increasing urban heat island effects, air pollution, pollution of water bodies and decrease of portable water. However, increasing designed landscapes in the urban areas have had a positive impact on the reduction of the adverse effects of urbanization. Nevertheless, it is evident that these newly designed spaces and locations are not sufficiently popular among the people. As previously mentioned, the main reason for this has been the negligence of the user preferences while designing the spaces (Ramanujam, 2007).

The relationship between the environment and people has a history with millions of years and it is a very strong and deep relationship. Landscapes can be either a reflection of a natural process or cultural changes through time, which means an existing landscape can be either a result of a natural process or has evolved through human intervention. Whichever way they come into being, they are experienced by people, through the central mechanism of perception which lies at the heart of people-place interactions (Min, 2012). 
Peoples' sensory organs play a vital role in their preferences for one place over the other. These sensory organs are stimulated by different stimuli present in the environment. The stimuli are converted into sensations by the sensory organs and these sensations are transmitted to parts of the brain to be interpreted. This process is known as perception in psychological terms. Perception is the process of deriving information through the senses and organizing and interpreting them. This can be defined as an active process taking place in between the organisms and the environment (Kaplan \& Kaplan, 1989).

Perception includes mainly two processes as sensational interpretation and the interpretation through past experience (Sharma, n.d.). As Gurr (1996) explains, behaviour is a result of the perceptual mechanism. Thus, a space that influences positively on an individual's perception contributes to a reciprocal behaviour or activities (Mumcu et al., 2010). Another inquiry by Porteous (1996) proves that perception receives information via our senses. Out of the five senses, sight is valued as the most important. He claims that more than $80 \%$ of an individual's sensory perception is through the sight (Kaymaz, 2012). This shows that visual perception is the most important in sensory perception.

People are involved with the environment to survive; they shape the environment in order to meet their expectations. While shaping the environment, people are also inspired and shaped by the environment. This relationship between the environment and Man is known as the 'Landscape Perception'. Thus, this relationship between the people and the environment as well as the perception of the environment have been a major concern in many fields of studies (Kaymaz, 2012). Perception is sometimes interpreted as a preference in many documents. Many researchers claim that, "Perception is a key element in preference and the measurement of preference permits an examination of perceptual process"(Kaplan \& Kaplan, 1989). There are many factors which affect the perception or the preference of a particular person as the gender, educational levels, cultural backgrounds and many more.

As mentioned, modern human perception and behaviour is linked with many biological instincts or behaviours. This paper investigates the concept, 'to see without being seen' to be true or false corresponding to the modern day. Along with the hypothesis that there are still biological instincts featured in the behaviour of the modern Man, the paper attempts to prove a simple part of the Appleton's Prospect and Refuge theory. The outcome of this paper will help to explore more on the biological behaviours of the modern Man and thus the results can be accommodated in the design processes. Since these designs automatically address the hidden biological instincts, the perception of the users will be positive to the respective designed spaces. Finally, the common spaces will automatically be userpreferred and there will be no more abandoned or unused public spaces.

\section{Theoretical Basis: Human Behaviour}

In strenuous, dangerous or life-threatening situations; behaviour patterns of some people don't belong to the 'normal' spectrum of human behaviour. These types of behaviours refer to the 'primitive' category since these are the true instinctive behaviours which have originated from early developmental stages. Simultaneously, such behaviours are also addressed as the biological behaviours or the behaviours originated as a result of the biological instincts. These behaviours origin in phylogenetically old, autonomous parts of the human brain (Schäfer, 2005).

Primitive human behaviours are the symbolic behaviours which are transferred from generation to generation. These behaviours are sometimes connected with particular spaces or the environment surrounding an individual (Vygotsky et al., 2013). This is because the origins of such behaviours are in the earliest ages of human existence where people depended on hunting. One such example of a primitive behaviour is the preference for the spaces which allows us to see the surrounding without exposing us to the others in the surrounding. This is based on the principle of hunting where the hunter must stay out from the view of the prey if they want the hunt to be successful. This paper discusses mainly this scenario and the existence of such primitive behaviours among the present urban park users (Vygotsky et al., 2013). One of the authors who have discussed this primitive behaviour more comprehensively is $\mathrm{J}$. Appleton. He proposes the existence of this behaviour through the Prospect and Refuge Theory.

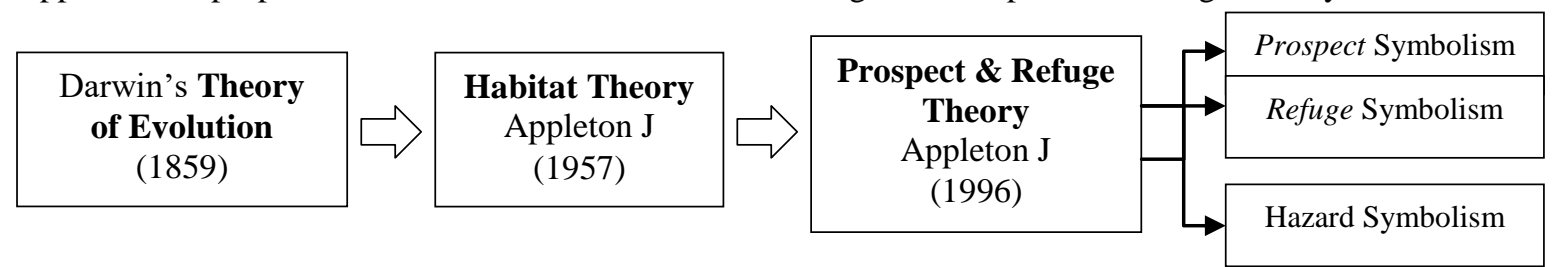

Fig. 1: Evolutional stages of the Prospect and Refuge Theory Source: Author 
With the concept of Darwin's theory (1859), Appleton (1957) derives the Habitat theory which implies that, an individual's perceived environment is same as that of an organism's relationship with its habitat. Despite an environment being favourable for survival or not, if that particular environment provides aesthetic satisfaction through spontaneous perception, then such a proposition is called Habitat Theory. Appleton says that "Habitat Theory, in short is about the ability of a place to satisfy all our biological needs"(1996;63). Through Habitat Theory, Appleton derives Prospect Refuge theory extending the Lorenz's (1964) phrase 'to see without being seen' as a primitive human behaviour. This theory narrows the scope of the Habitat theory. From all the factors which cause aesthetical satisfaction, this theory considers the prospect, refuge and hazard symbols only. Appleton has described the prospect and refuge symbols as "Where he has an unimpeded opportunity to see we can call it a prospect. Where he has an opportunity to hide, a refuge"(Appleton, 1996). Appleton (1996) further describes that whenever there is a chance to observe without being noticed by the others, then the aesthetic perception is attended with pleasure with no anxiety. Primarily this theory discusses the primitive defensive behaviour of human beings. It analyses mainly two abilities; the ability to move and the ability to perceive (Ramanujam, 2006).

Appleton suggests that, "Prospect symbolism and refuge symbolism also demand a hazard symbolism to make them work"(1996;85). By abolishing the prospect and refuge symbolism, one can eliminate a hazard completely. The symbolism of hazard or danger may not represent a real danger or a hazard. But still it will create a sense of danger in a person. These two terms - prospect and refugecannot be identified as a dichotomy of opposites. It is crystal clear that the opposite of 'to see' is not 'not to be seen'. A landscape which affords both a good opportunity to see and a good opportunity to hide is aesthetically more satisfying than one which affords neither, but again a weakness in prospect or in refuge may be compensated for, by the strength in the other (Appleton, 1996).

The balanced Prospect-refuge symbols have been used throughout history with the evolution of Man irrespective of country or religion. When it comes to the survival of Man, he had to face natural hazards like rain, wind and intense sunlight. For these purposes, Man began to build settlements to live. The earliest of the settlements was rock dens (especially at the middle of a huge rock mountain) and small huts built on trees. These settlements were also for assuring safety from the natural hazards as well as animal hazards. The elevated areas allowed observing the surrounding area and rock dens and huts on trees were ideal so that the observer is not seen to the others. As mentioned earlier, hunter gathering era was the period when the concept of 'to see without being seen' has come into being. Man waited in the edge of the open area covered in closure so that he can target the prey very easily without being noticed by the prey. In such occasions, the edge environment of the prospect and refuge were more advantageous for Man (Ramanujam, 2007).

As Lothian (1999) claims, there are two contrasting paradigms in perception as objectivism and subjectivism which claim that preference is based either on the physical attributes or on the individual observer respectively (Cheng, 2007). This study employed this theory and examined the subjective perspective of landscape perception. The study accommodates only the perception of the people which means that this study tends more towards the psychological examination of the preference.

\section{Research Methodology}

The study of Nasar (1983) and his team has accompanied scenarios with closed view, and open view from a protected or non-protected observation point (Dosen \& Ostwald, 2012). The same methodology is used in this study as well. The first space, Strong Prospect symbolism scenario consists with an open view as well as with an open observing point. The second space is with an enclosed view but with an open observing point has been termed as the Inversely balanced Prospect Refuge scenario since it provides completely opposite environmental conditions to the concept 'to see without being seen'. The third space which consists of an open view and an enclosed observing point has been reinterpreted as the perfectly balanced Prospect-Refuge symbolism scenario. This is the perfect space which allows the user to observe the surrounding while providing the best environmental conditions with an enclosed observing point which allows not to be seen by the others. The final or the fourth space is with an enclosed view as well as an enclosed observing point which is termed as the strong refuge symbolism scenario where the whole area as well as the observing point is closed. 


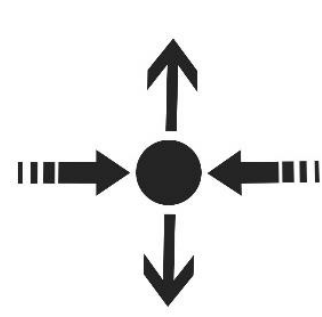

Strong Prospect

(Open view with an open observing point)

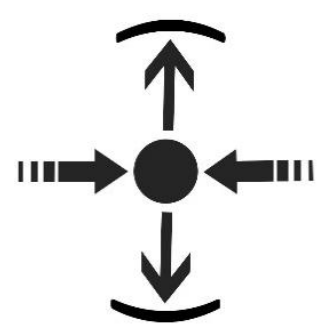

Inversely balanced

(Enclosed view with an open observing point)
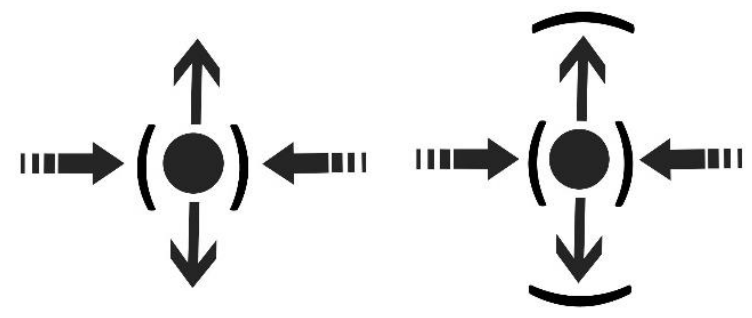

Perfectly balanced

\section{Strong refuge}

(open view with an enclosed observing point)

(Enclosed view with an enclosed observing point)

Source
Blockin $\begin{aligned} & \text { Views towards } \\ & \text { the surrounding } \\ & \text { Views from the } \\ & \text { surrounding }\end{aligned}$

Fig. 2: Diagram explaining the nature of the Selected scenarios Source: Author

In order to compile a measurable scale for this perspective, the authors incorporated the findings of the research paper "A reliable and valid self-rating measure of the restorative quality of natural environments" by Ke - Tsung Han. With the use of Kaplan and Kaplan's (1989) theory and Ulrich's (1983) theory, the authors built up a 'restoration scale' using four main dimensions as emotional, physiological, cognitive and behavioural. This restoration scale is a self - measurement scale of the preference and was titled as the "short-version revised restoration scale" where each dimension is evaluated with two variables amounting to total of eight variables.

The physiological dimension evaluates the physical changes connected with the perception of an individual. But, as Sri Lanka is a tropical country which doesn't experience seasonal changes and only experience the rainy season and the dry season, the physiological dimension has been removed and only the emotional, cognitive and behavioural changes are analysed here. The meaning of 'emotion' is 'the conscious pleasure characterized by intense mental activity and a certain degree of pleasure or displeasure'. The word cognitive suggests, 'the functions connected with thinking or conscious mental process'. The behaviour is 'a particular way of acting' as stated in the Cambridge dictionary (Han, 2003). Many researches like Horney (1954), Schneirla (1959), Mehrabian and Russell (1974) have agreed that the preference of an individual is a measure of his/her approach and avoidance to a certain space or a circumstance. Finally, the study investigates three dimensions of perception as Behavioural, Emotional and Cognitive.

The sample selection for the study has been carried out based on the four research paradigms of landscape perception assessment as developed by Zube, et.al (1982) which are expert, psychophysical, cognitive and experiential paradigms. The Expert paradigm and the psychophysical paradigm has been used in this study where the expert paradigm (Final year students of the Bachelor of Landscape Architecture degree) is the information obtained by the skilled and trained observers and the psychophysical paradigm claims the assessment through the general users of the area. Although two categories of users are selected, both the user categories comprise of the urban dwellers. The general users to the selected parks were chosen randomly. The research was carried out with the revised, short-version restoration scale by Han (2003) with the five - point Likert scale. A questionnaire and short interviews were carried out in order to obtain the necessary data.

\section{Case Studies: Beddagana Wetland Park and Diyasaru Park}

Several locations within The Beddagana wetland park and the Diyasaru park; urban wetland parks in the suburbs of Colombo in close vicinity of the parliament have been selected as the case studies for this study. 


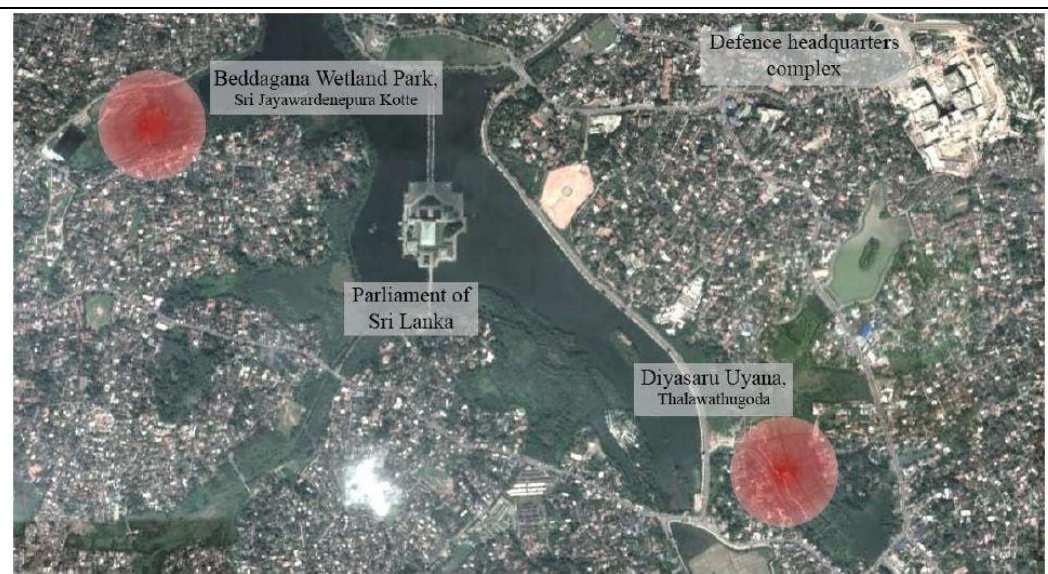

Fig. 3: Selected case study locations Souce: Authors

First, the authors visited the selected parks and the spaces where the people were gathered for a longer time period or the spaces they seem to be interested (through observation) were recorded. Then the physical characteristics of each space were sketched and analysed. Afterwards, along with some expert interviews (lecturers of the Degree course on Landscape Architecture) the following spaces were selected according to the criteria mentioned in Fig. 2 above. (Under the four types of spaces as strong prospect symbolism, inversely balanced prospect and refuge symbolism, perfectly balanced prospect refuge symbolism and the Strong refuge symbolism).

Randomly selected users were interviewed through a questionnaire and interviews. The authors provided the questionnaire after their visit to the park and collected their perception scores through a 5-point Likert scale. In the case of the experts, the authors directed them to the spaces in sets of five and they were provided with separate questionnaires for their individual scores. Then the authors collected further explanations for their preferences through interviews. Here the data were recorded using recorders. A total of 30 experts (expert paradigm) for each park and 30 everyday users (psychophysical paradigm) for each park were interviewed.

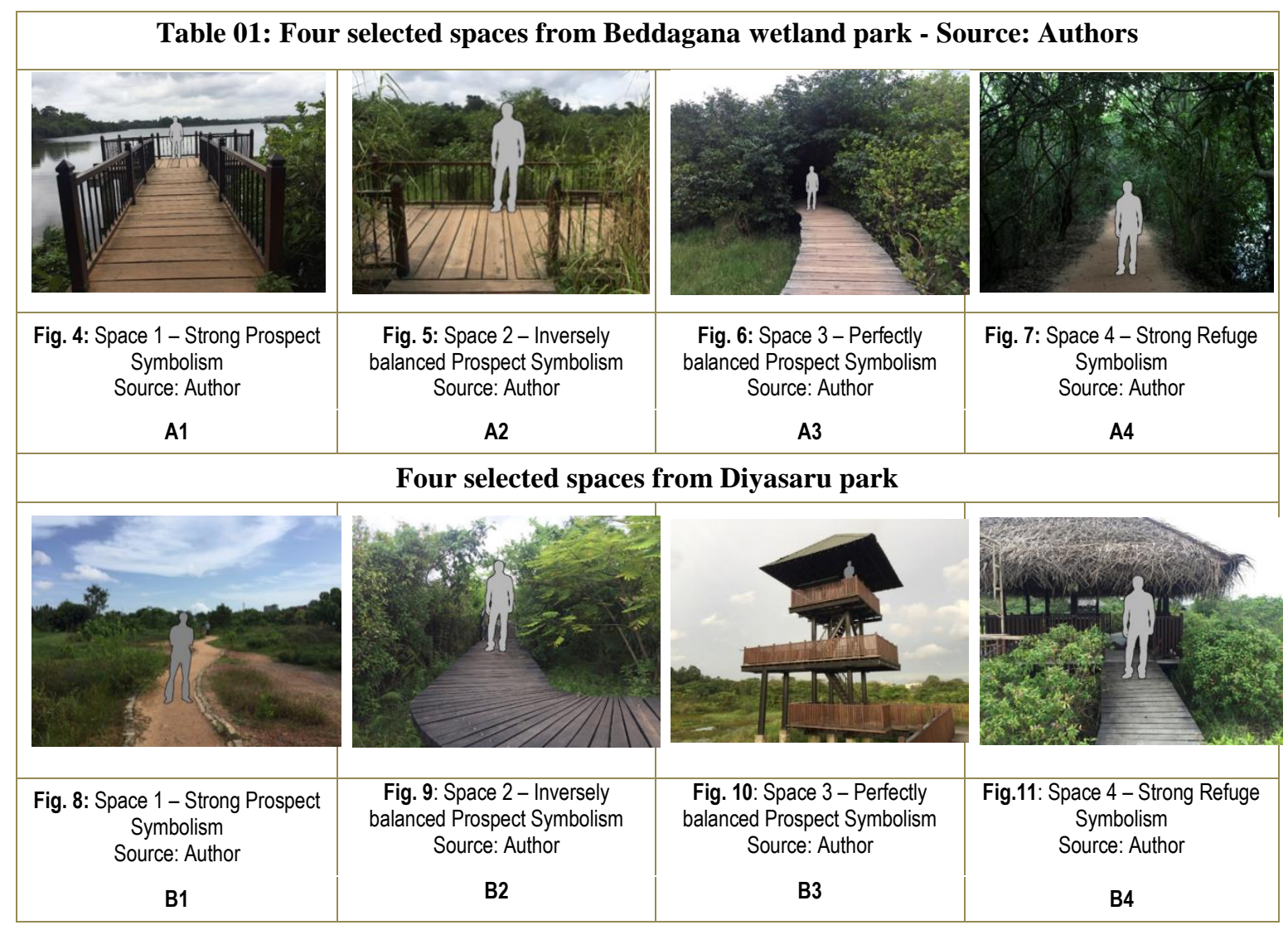


The data collected from the every-day users as well as the experts were then analysed with the mean values of the scores obtained from the Likert scale and the explanations for the respective preferences were analysed through the data obtained from the interviews. The data analysis was extended further with a statistical analysis with Mann Whitney $U$ test (to test the contribution from each type of user category for the final preference score) and Spearman's Correlation (to assess the impact from the behavioural, emotional and cognitive dimensions of the preference).

\section{Results and the Discussion}

\begin{tabular}{|c|c|c|c|c|c|c|c|c|}
\hline & \multicolumn{2}{|c|}{ Open-Open } & \multicolumn{2}{|c|}{ Open-Close } & \multicolumn{2}{|c|}{ Close-Open } & \multicolumn{2}{|c|}{$\begin{array}{l}\text { Close - } \\
\text { Close }\end{array}$} \\
\hline \multirow{2}{*}{$\begin{array}{l}\text { Scenarios } \\
\text { Space }\end{array}$} & \multicolumn{2}{|c|}{$\begin{array}{c}\text { Strong } \\
\text { Prospect }\end{array}$} & \multicolumn{2}{|c|}{$\begin{array}{l}\text { Inversely } \\
\text { Balanced }\end{array}$} & \multicolumn{2}{|c|}{$\begin{array}{l}\text { Perfectly } \\
\text { Balanced }\end{array}$} & \multicolumn{2}{|c|}{$\begin{array}{l}\text { Strong } \\
\text { Refuge }\end{array}$} \\
\hline & A1 & B1 & $\mathrm{A} 2$ & $\mathrm{~B} 2$ & $\mathrm{~A} 3$ & B3 & $\mathrm{A} 4$ & B4 \\
\hline \multicolumn{9}{|c|}{ Normal users (Psychophysical paradigm) } \\
\hline Emotional & 4.10 & 2.10 & 3.47 & 3.77 & 4.53 & 4.00 & 3.57 & 4.37 \\
\hline Cognitive & 3.67 & 2.20 & 3.47 & 3.67 & 4.43 & 3.80 & 3.33 & 3.97 \\
\hline Behavioral & 4.10 & 2.40 & 3.47 & 3.83 & 4.87 & 4.13 & 3.40 & 4.37 \\
\hline Overall & 4.20 & 2.13 & 3.47 & 3.73 & 4.87 & 4.40 & 3.53 & 4.07 \\
\hline Aesthetic response* & 3.96 & 2.23 & 3.47 & 3.76 & 4.61 & 3.98 & 3.43 & 4.23 \\
\hline Rank & 4 & 8 & 6 & 5 & 1 & 3 & 7 & 2 \\
\hline \multicolumn{9}{|c|}{ Users with a design background (expert paradigm) } \\
\hline Emotional & 3.83 & 2.33 & 3.27 & 3.87 & 4.43 & 4.17 & 3.33 & 4.13 \\
\hline Cognitive & 4.00 & 2.63 & 3.00 & 3.80 & 4.73 & 4.17 & 3.57 & 4.07 \\
\hline Behavioral & 3.80 & 2.13 & 2.67 & 3.57 & 4.37 & 4.23 & 3.47 & 4.20 \\
\hline Overall & 4.20 & 2.67 & 3.47 & 3.67 & 4.87 & 4.33 & 3.67 & 4.07 \\
\hline Aesthetic response* & 3.88 & 2.37 & 2.98 & 3.74 & 4.51 & 4.19 & 3.46 & 4.13 \\
\hline Rank & 4 & 8 & 7 & 5 & 1 & 2 & 6 & 3 \\
\hline \multicolumn{9}{|c|}{ Combined perception values for all the users } \\
\hline $\begin{array}{l}\text { Average (Individual } \\
\text { spaces) }\end{array}$ & 3.92 & 2.30 & 3.22 & 3.75 & 4.56 & 4.08 & 3.44 & 4.18 \\
\hline Average (scenarios) ${ }^{2}$ & \multicolumn{2}{|c|}{3.11} & \multicolumn{2}{|c|}{3.49} & \multicolumn{2}{|c|}{4.32} & \multicolumn{2}{|c|}{3.81} \\
\hline Rank & \multicolumn{2}{|c|}{4} & \multicolumn{2}{|c|}{3} & \multicolumn{2}{|c|}{1} & \multicolumn{2}{|c|}{2} \\
\hline
\end{tabular}

Table 2 - The summary of subjective perspective (psychophysical and expert paradigms) Source: Authors

The overall results (Table 2 above) depicted that both user groups had the highest preferred scene as the third space; A3 (Perfectly balanced prospect refuge symbolism) of the Beddagana wetland park. The fourth space; B4 (Strong Refuge Symbolism) of the Diyasaru park has been scored as the second most preferred scene. The least preferred scene for both the user groups has been the first space of the Diyasaru park; B1 (Strong Prospect symbolism). When considered with the four separate scenarios, the Perfectly balanced scenario has the highest overall preference and the strong refuge, inversely balanced and strong prospect scenes have been the second, third and fourth preferences respectively.

Apart from the data obtained from the Likert scale in the questionnaire, the research gathered the reasons for the above preferences from the users through the interviews. 53 of the selected users (from the experts -30; and every-day users (Psychophysical paradigm - 30) claim that the strong prospect scenery has been preferred more in the case of the Beddagana wetland park due to the presence of water in the vicinity as it cools down the surrounding. The inversely balanced prospect refuge symbolism of Diyasarupark has been preferred more due to the scale and the nearness of the surrounding elements since it has provided more shade making the space friendlier and pleasing (48 responses). According to the data collected from the interviews, the preference scores for the perfectly balanced scene of Beddagana wetland park has been higher because of the depth of the view and the scale of the elements surrounding vegetation. Similarly the results from the interviews showed that, the strong refuge scene of the Diyasarupark also has been preferred more due to the scale and the environmentally friendly surrounding in the middle of the wetland.

The results from the Mann Whitney U test confirmed that both the psychophysical paradigm (every day users) as well as the experts have been similar thus proving that there is no difference on the preferences 
due to the educational level or the appreciation abilities of the aesthetics. The graph above shows an averaged value of both the user groups for each location.

The Spearman's correlational analysis with the three different dimensions and the total preference score depicted that the behavioural dimension affected mostly in the case of Beddagana wetland park and the cognitive dimension has affected the perception of theDiyasaru park. The interviews revealed that the perception of the selected spaces in the Diyasarupark has been affected more by the cognitive dimension since the scenes were more attentive. Similarly, the interviews from the users in the Beddagana wetland park stated that the aesthetics and sceneries created an attractive surrounding in the park which kept them wandering in the park for a longer time period. Thus, the behavioural dimension has been affected more in the case of the Beddagana wetland park. The scores for the other two dimensions have also been significant according the correlation analysis proving that all the dimensions have contributed significantly to the final result of the preference.

\section{Conclusion}

The conclusion from the above results has proved that there are no differences in the preferences of the experts with a designing ability in relation to the landscape design and the general users. The highest preference from both the user groups has been towards the perfectly balanced prospect refuge scene. What this suggests is that the users of both user groups prefer to observe the open view of the surrounding while standing at an enclosed observing point. This concludes that the ideal scene which satisfies the ability to see without being seen is mostly preferred. The hunter gathering era had used this concept for their daily hunts. The spaces which allowed the hunter to see the prey without being seen by the prey was preferred in that era as it eased their hunt. These preferences have always been affected by the emotional, cognitive as well as behavioural patterns and thoughts related. Although this study is limited only to a specific sample size and two case studies only, the same study can be further extended with the gender differentiation analysis and differentiations with the urban and non-urban dwellers, different cultural backgrounds etc. with a larger sample size with more case studies. The impact from the objective perception which claims that the preference of the people lies in the physical environment can also be studied as an extension to this study.

The findings of this study suggest that still, people prefer spaces corresponding to the biological instincts (spaces which provide the ability to see without been seen as per this study). It thus promotes further studies on the different biological aspects thus so that these biological aspects can be considered when designing spaces.

\section{References}

Appleton, J. (1996). The experience of landscape (Rev. ed). John Wiley and sons. https://trove.nla.gov.au/version/45659942

Cheng, C.-K. (2007). Understanding visual preferences for landscapes: An examination of the relationship between aesthetics and emotional bonding [Unpublished Doctoral dissertation, A\&M University]. http://oaktrust.library.tamu.edu/bitstream/handle/1969.1/etd-tamu-1375/cheng-dissertation.pdf?se quence $=1$

Dosen, A. S., \& Ostwald, M. J. (2012). Testing Prospect-Refuge Theory: A Comparative Methodological Review. 46th Annual Conference of the Architectural Science Association, Griffith University, 8.

Han, K.-T. (2003). A reliable and valid self-rating measure of the restorative quality of natural environments. Landscape and Urban Planning, 64, 209-232. https://doi.org/10.1016/S0169-2046(02)00241-4

Kaplan, R., \& Kaplan, S. (1989). The Experience of Nature: A Psychological Perspective. Cambridge University Press.

Kaymaz, I. C. (Ed.). (2012). Landscape Perception. In Landscape Planning Edited by Dr. Murat Ozyavuz (p. 360 pages). InTech Europe. https://www.intechopen.com/books/landscape-planning/landscape-perception

Min, B.-W. (2012). An Ecological Aesthetic in Sustainable Landscape Design. Journal of the Korean Institute of Landscape Architecture, 40(2), 38-48. https://doi.org/10.9715/KILA.2012.40.2.038

Mumcu, S., Duzenli, T., \& Ozbilen, A. (2010). Prospect and refuge as the predictors of preferences for seating areas. Scientific Research Essays, 05, 11.

Mutso, M. (2014). Preferences for landscape openness and its influence on recreation (Master's Thesis). Eesti Maaulikool Estonian University of Life Sciences, Estonia.

Nasar, J. L. (1997). New Developments in Aesthetics for Urban Design. In Toward the Integration of Theory, Methods, Research, and Utilization (pp. 149-193). Springer, Boston, MA. https://doi.org/10.1007/978-1-4757-4425-5_5 
Ramanujam, P. (2006). Prospect refuge theory revisited: A search for safety in dynamic public spaces with a reference to design. Thesis, 148.

Ramanujam, P. (2007). Prospect-refuge theory revisited: a search for safety in dynamic public spaces with a reference to design.

Schäfer, A. (2005). Human Primitive Behavior (pp. 189-204). https://doi.org/10.1385/1-59259-872-2:189

Sharma, A. (n.d.). Perception: Meaning, Definition, Principles and Factors Affecting in Perception. Psychology Discussion. Retrieved May 29, 2018, from http://www.psychologydiscussion.net/perception/perception-meaning-definition-principles-and-f actors-affecting-in-perception/634

Vygotsky, L. S., Luria, A. R., \& Knox, J. E. (2013). Studies on the History of Behavior: Ape, Primitive, and Child. Psychology Press.

Zube, E. H., Sell, J. L., \& Taylor, J. G. (1982). Landscape perception: Research, application and theory. Landscape Planning, 9(1), 1-33. 